\title{
MODULATION ACTIVITY OF AYURVEDIC ANTIOXIDANTS AGAINST OCHRATOXIN (OTA) TOXICITY
}

\author{
Y. Karamalakova, G. Nikolova* \\ Department Chemistry and Biochemistry, Medical Faculty, Trakia University, \\ Stara Zagora, Bulgaria
}

\begin{abstract}
People and animals are constantly exposed to the harmful effects of Ochratoxin A (OTA) inducedtoxicity, by food. Despite the numerous scientific developments, the problems about damageable effect remain unsolved. The aim of this report is to evaluate and discuss the high protective and antioxidant properties of some Indian Ayurvedic plants (Curcuma longa, Tinospora Cordifolia and others) against OTA induced toxicity in blood and organs.
\end{abstract}

Key words: OTA, damages, Indian Ayurvedic plants, protective properties

\section{INTRODUCTION \\ 1. Mycotoxins.}

The natural antioxidants increasingly are used for therapeutic purposes, worldwide. However, various pollutants and harmful micotoxins located mainly in food and feed permanently damage the health of animals and humans. Over the last decades, has been explored the possibility of preventing the toxic effects of various mycotoxins by combining them with endogenous antagonist components contained in medicinal herbs and spices [1]. Mycotoxins are group of structurally diverse fungal secondary metabolites belonging to the Aspergillus, Penicillium and Fusarium species. As metabolising agents they participate in the food chain through contaminated cereals or animal products (feed). Mycotoxicosis is the major health problem caused by mycotoxins, but mycotoxin-induced physiological, immunological and other disorders were observed. Aflatoxins, fumonisin B1, deoxynivalenol, zeralenone, $\mathrm{T} 2$ toxin and spesially ochratoxin A (OTA) were the most studied mycotoxins [2, 3, 4]. Given their

*Correspondence to: Galina Nikolova, Department Chemistry and Biochemistry, Medical Faculty, Trakia University, 11 Armeiska Str., 6000 Stara Zagora,Bulgaria, gallina_nikollova@abv.bg chemical structures (lactones and coumarins) and biological effects, mycotoxins were classified as hepatotoxins, nephrotoxins, neurotoxins, immunotoxins, carcinogens, mutagens and others. [5].

Based on these facts, this critical review focuses on the modulative action of some natural Ayurvedic plants - antioxidants on in vitro and in vivo ochratoxin A toxicity, at the molecular and cellular level.

\section{Ochratoxin-A.}

Practically, $(\mathrm{R})-\mathrm{N}-[(5-$ chloro-3,4-dihydro-8hydroxy-3-methyl-1-oxo-1H-2-benzopyran-7yl)carbonyl)-1-phenylalanine (OTA) (Figure1), is an organic soluble mycotoxin, territorially recognizable and detected at all stages of the food chain (cereals, meat, fruit, coffee, etc.) due to favorable weather conditions, additional humidity, improper storage of food components $[6,7]$.

The complicated OTA toxic action is not the fully elucidated, but possibly lead to the induction of oxidative stress, inhibition of protein synthesis, formation of DNA adducts, which is known for its genotoxicity and carcinogenicity, apoptosis, cell cycle arrest [8, 9]. The complete OTA elimination from contaminated food is practically impossible due to its high thermal stability [10], full 
absorption from the gastrointestinal tract, and resulting in a longer half-life in the body [8, 11]. The multiple previous epidemiological studies have been shown to OTA predisposes to tumors in animals involved in the pathogenesis of a large number of human nephropathies, renal toxicity and proven carcinogenicity [10]. The OTA also has an adverse effect on production of energy followed by the cellular dysfunction and a sharp reduction in protein synthesis and electron transport $[11,12]$, predisposing to oxidative changes. OTA oxidative damages is probably due to a number of chemical processes in the cell, activation of peroxidases, and the preparation of phenoxyl and superoxide anion radicals, resulting in additional cell-oxidative stress and destruction [13]. Many authors emphasize that the OTA
KARAMALAKOVA Y., et al. leads to excessive formation of reactive oxygen species (ROS), such as the superoxide anion $\left(\mathrm{O}_{2} \cdot\right)$, hydroxyl radical $(\cdot \mathrm{OH})$ and peroxide (ROO·), and irreversible oxidative damage to lipids, proteins and DNA damages, in in vitro and ex vivo models [5, 6]. Attentive data analysis has shown that OTA-treated cells simultaneously increase ROS levels, reactive nitrogen species (RNS) and peroxynitrite formation (ONOO-) [13, 14]. The elevated OTA toxicity strongly correlated with reducing the protein activators levels and additional cytoprotective enzymes, followed by lowering the antioxidant defense system in the cells or body $[6,15]$. Belmadani et al have shown that the toxic OTA effects were due to prolonged oxidative damage processes in mammalian cell lines and primary cells [16].

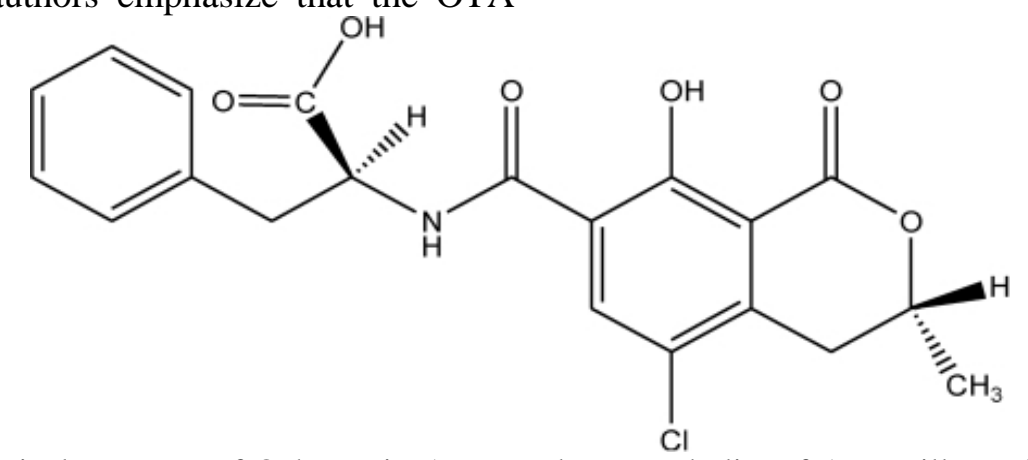

Figure 1. Chemical structure of Ochratoxin-A: secondary metabolite of Aspergillus ochraceus and Penicillium verrucosum species, caused nephropathies, DNA/RNA damages and urothelial tumors in animal and human body.

Few previous studies have reported a decrease in lipid peroxidation and oxidative changes in animals treated with OTA and natural antioxidants compared to animals treated with OTA, alone [17]. Several research groups showed that the flavonoid aglycones such as galangin and quercetin can significantly suppressed OTA-induced cytotoxicity and oxidative stress. $[18,19]$. Aim of our previous study [20] was to verify whether OTA can induce oxidative processes causing overproduction of ROS, reactive nitrogen species (RNS), and subsequent lipid and per oxidative lesions that ultimately lead to oxidative stress in organs and blood. Male ICR albino mice were included in the control diet supplemented with OTA. After 28 days of treatment the mice were killed and the spleen and blood plasma of each mouse are collected and homogenized to assess biochemical parameters in urine and plasma. Furthermore, the EPR analysis showed that OTA administration caused significantly increased levels of Ascorbate (Asc) and NO radicals and ROS production, as well as damage of the antioxidant defense system. It was also observed that OTA chronic consumption induced a significant increase in $8-\mathrm{OHdG}$ production, which probably due to DNA fragmentation in the studied spleen tissue. These results confirmed that OTA exhibited toxicity to different organs but most susceptible to its toxicity was the spleen $[5,14$, $15]$.

\section{Ochratoxin A Toxicity: The Protective activities of Ayurveda herbal antioxidants.}

A number of in vitro and in vivo studies have been carried out to eliminate or reduce OTA toxic levels in foods and human health, using physical (division, sorting, purification), chemical (ammonium, hydrolyze, bisulfites, ozone) and microbiological (A. niger strain, lipase, metalloenzyme) methods [21]. Antioxidants of different nature that counteract the toxicity and carcinogenicity of mycotoxins are described in a number of studies. Various food antioxidant supplements, as melatonin, ascorbic acid, retinol, tocopherol, and others were used, as protectors against OTA-toxicity 
[21a; 21b]. Antioxidant herbal control of mycotoxin contamination is the best method of protection. Indian traditional herbs from the system of Ayurveda, known for their advantages and therapeutic potential and security [22] have been used for strengthening the body/immune system to fight against various diseases [23]. Herbal antioxidants have proven anti-inflammatory, antibacterial, antiviral and antifungal properties, proven in people suffering from colds, allergy and rheumatoid diseases; bacterial and skin infections, chemical intoxication [24] and useful for treating cancer diseases. In the present decades of antibiotic resistance, high toxicity of synthetic drugs and side effects residues in food, natural remedies are better suited for animal and human health. The majority of natural agents were in vitro and in vivo studied with proven benefits, low cost and general safety [25]. The main advantages of herbal medicine in comparison with conventional medicine is to identify and treat the root cause of the disease with minimal side effects, easy administration of herbs as a tincture, tea or mixed with food/ water and not least without drug resistance and serious consequences environment [25, 26]. Ayurvedic herbs as typical antioxidants comprise multiple bioactive molecules (alkaloids, steroids, diterpenoid lactones, aliphatics, glycosides, polyphenols, theaflavins, vitamin $C$, carotene, fluoride, zinc, selenium), which prevent the disease conditions, stimulate the immune system and increase the ability on protection against cancer [25].

The aromatherapy with essential oils extracted from various parts of Ayurvedic herbs has proven therapeutic effect in cancer treatment [22], lower cytotoxicity, carcinogenesis, and also strong free radical scavenging properties against reactive oxygen/ nitrogen species, and oxidative stress elimination [27, 28, 29]. Plant antioxidants are able to reduce oxidative stress either by scavenging ROS or repairing damages. Many studies have shown that the presence of highly active biomolecules (alkaloids, polyphenols) in aqueous-/ alcoholic extracts of Indian herbs possess detoxicative effect against OTA and protection of aflatoxininduced organ toxicity $[5,29,30,31]$.

\section{Regulation of the Ochratoxin-toxicity by Ayurvedic Plants}

The main purpose of this review is briefly to describe the need to use ayurvedic plants as
KARAMALAKOVA Y., et al.

reducing agents of toxicity and oxidative damage caused after the OTA application. Ayurvedic plants have the ability to stimulate the antioxidant and potential defense mechanisms of the body from poisoning due to OTA, traditional use and modern trends.

\section{Withania somnifera $L$.}

Botanical name- Withania somnifera;

Natural order - Solanales;

Family-Solanaceae;

Indian name - Ashwagandha, Apocynaceae, Indian ginseng, available in the form of fine powder, is a well-known herb possessing several therapeutic activities and maintaining general health like: immunomodulation, diuretic, rejuvenator, stress reliever, anticancer, anti-epileptic, cardio-respiratory endurance enhancer, anti-ageing, hypoglycemic, antioxidant. As powerful antioxidant and detoxifying agent is possible to protect cellular damage caused by free radicals and oxidative stress [32]. After a lengthy administration of Withania somnifera (17 weeks) have been registered a decrease in cyclophosphamide-induced leukopenia. New research reported that the potential of the natural antioxidant is in the regulation of the metal-induced toxicity and lipid peroxidation and also the significant reduction of Ochratoxin-A induced suppression of the chemotactic activity as well as interleukin IL-1 and TNF-alpha [32, 33].

\section{Tinospora cordifolia Miers}

-Natural order-Liliaceae;

Ranunculales;

- Family- Menispermaceae;

Indian name: guduchi, amrta, cinnodbhava, Amruthu, Chittamruthu, used as typical antioxidant, has been appreciated as an important drug of the Indian system of medicine and used in Ayurvedic preparations as a compound with a variety of active components (alkaloids, steroids, diterpenoid lactones, aliphatics, and glycosides). This herb possesses antistress, antidiabetic, antiulcer, anti-oxidative, hepato- and radioprotective properties. Extracts of this plant are thought to be inducers of other antioxidant agents and significant reducers of chemotherapy-induced free radical toxicity and lipid peroxidation levels. They show also a detoxifying effect against OTA toxicity and protect against aflatoxin-induced organ toxicity $[10,34]$.

\section{Asparagus racemosus Willd.}

-Botanical name: Asparagus racemous;

-Natural order: Liliaceae; 
-Indian name: Shatavari; Satavari, Satawar or Satmuli, used in traditional Ayurveda, for its highly mucilaginous, galactogogue, diuretic, nutritive, tonic, demulcent, antiulcer, antitussive, antibacterial, antioxidant activities and for stress-related immune disorders. The fresh extract was shown to exert a strong inhibitory effect on pro-inflammatory cytokines and tumor necrosis factor (TNF), and on the production of nitric oxide and inhibition of OTA- induced toxicity [25, 35]. Extracts of Asparagus racemosus, Tinospora cordifolia and other plants significantly inhibited carcinogen OTA-induced suppression of chemotactic activity and production of IL1 and TNF- $\alpha$ [36].

\section{Curcuma longa $L$.}

-Botanical name: Curcuma longa;

-Natural order: Zingiberales;

-Family: Zingiberaceae;

-Indian name: Haldi; Indian saffron; yellow ginger, used in traditional Indian herbal medicine has strong anti-inflammatory effect and is used for: skin diseases, constipation, internal injuries, eye diseases, wounds, galactagogue, external parasites, mastitis, cold, bone fractures, foot, hematuria and stomach pains. Curcumin, as the main component in the plant structure, possesses antioxidant activity and exerts anticancer effects in ovarian, skin, colon and duodenum. It was also used as an anti-Alzheimer agent, as hypoglycemia and hepato-protector. Many authors have reported that after testing of Curcuma Longa powder (feed additive) is achieved decreasing the overall OTA-toxicity and hepatoprotective impact of raising chickens [37,38]. Generally, the use of Curcuma Longa, as an antioxidant and protector, led to a decrease of the intensity of histopathological changes; change the weight of the bodies, an increase in body weight and an improvement of hematology and biochemical parameters [38]. Powder alleviated AFB1-suppressed antioxidant activity, such as peroxides and superoxide dismutase (SOD) activity, and total antioxidant concentration in liver homogenates. Gowda et al., 2008 ported that the powder of yellow ginger alleviates superoxide dismutase and antioxidant activity concentration in the liver homogenates, after exposure to aflatoxins [39].

\section{Glycyrrhiza glabra $L$.}

-Botanical name: Glycyrrhiza glabra;

-Natural order: Fabales;

Family: Fabaceae; Liquorice;
KARAMALAKOVA Y., et al. Ayurvedic plants, used commonly for various purposes as: inhibits ROS generation, antiinflammatory agent, anti-viral activity against HIV, potent immune-modulator and antioxidant [25]. Glycyrrhiza glabra extracts have been used in traditional medicine for increased blood pressure, hypokalemia and muscle weakness [40, 41]. Malekinejad et al., reported that Glycyrrhiza glabra compounds minimized the detrimental effects of OTAinduced toxicity in affected organs [42] and ameliorate OTA-induced cellular oxidative stress.

In addition, most of the main components in the herbs have a positive influence on the actions of mycotoxins as natural countervailing factors [1]. Herbal medicines such as antagonizing components by blending with OTA-mycotoxins, lead to metabolic inactivation and reduce the toxicity induced by the mycotoxins [1].

\section{CONCLUSION}

Due to their extensive pharmacological activities, interest in the use of herbal medications is constantly grows in modern medicine. Using of a correct dosing regimen for the powerful antioxidants, and effective monitoring, leads to an increase in their therapeutic efficacy. They by contrast exhibit as strong protectors, neutralizing OTAinduced toxicity and oxidative stress levels. Indian Ayurvedic herbs have an immense practical application in veterinary medicine and biomedicine, and powerful role in health maintaining.

\section{ACKNOWLEDGMENTS}

This study was supported by grants project PIRSES-GA-2012-316067-EU and scientific projects: 19/2013 and 6/2015, Trakia University, Stara Zagora, Bulgaria.

\section{REFERENCES}

1. Do, K., An, T.J., Oh, S.K., Moon, Y., Nation-based occurrence and endogenous biological reduction of mycotoxins in medicinal herbs and spices. Toxins., 7(10):4111-30, 2015.

2. Sweeney, M., Dobson, A.D.W. Mycotoxin production by Aspergillus, Fusarium and Penicillium species. Int. J. Food Microbiol., 43:141-158, 1998.

3. Oswald, I., Marin, D., Bouhet, S., Pinton, P., Taranu, I., Accensi, F., Immunotoxicological risk of mycotoxins 
for domestic animals. Food Addit. Contam., 22: 354-360, 2005.

4. Pfohl-Leszkowicz, A., Petkova-Bocharova, T., Chernozemsky, I., Castegnaro, M., Balkan endemic nephropathy and associated urinary tract tumours: A review on aetiological causes and the potential role of mycotoxins. Food Addit. Contam., 19: 282-302, 2002.

5. Sorrenti, V., di Giacomo, C., Acquaviva, R., Barbagallo, I., Bognanno, M., Galvano, F. Toxicity of Ochratoxin A and its modulation by antioxidants: A review. Toxins., 5: 1742-1766, 2013.

6. Kőszegi, T., Poór, M., Ochratoxin A: Molecular Interactions, Mechanisms of Toxicity and Prevention at the Molecular Level. Review. Toxins., 8(4): 111, 2016.

7. Malir, F., Ostry, V., Pfohl-Leszkowicz, A., Malir, J., Toman, J., Ochratoxin A: 50 Years of Research. Toxins (Basel).,4: 8(7), 2016.

8. Duarte, S., Pena, A., Lino, C., Ochratoxin A non-conventional exposure sources-A review. Microchem. J., 93: 115-120, 2009.

9. Amézqueta, S., González-Peñas, E., Murillo-Arbizu, M., López de Cerain, A., Ochratoxin A decontamination: A review. Food Control, 20: 326-333, 2009.

10.Karamalakova Y., Agarwal P., Nikolova G., Adhikari, M., Gupta, D., Stoev, S., Georgiev, T., Hadzhibozheva, P., Arora, R., Zhelev, Z., Raisuddin, S., Gadjeva V., and Zheleva, A., Influence of Ochratoxin-A And An Extract Of Tinospora Cordifolia Against Biochemical And Oxidative Changes In Mice Spleen. Science \& Technologies, Number 1: Medical Biology Studies, Clinical Studies, Social Medicine And Health Care, VI: 242-251, 2016.

11.Poór, M., Veres, B., Jakus, P., Antus, C., Montskó, G., Zrínyi, Z., VladimirKneževi'c, S., Petrik, J., K"oszegi, T., Flavonoid diosmetin increases ATP levels in kidney cells and relieves ATP depleting effect of Ochratoxin A. $J$ Photochem Photobiol B, 132: 1-9, 2014.

12.Wei, Y., Lu, T., Wei, R., Effect of Ochratoxin A on rat liver mitochondrial respiration and oxidative phosphorilation. Toxicol, 36: 119-123, 1985.

13.Murray, A., Kisin, E., Castranova, V., Kommineni, C., Gunther, M., Shvedova, A., Phenol-induced in vivo oxidative stress in skin: Evidence for enhanced free radical generation, thiol oxidation, and
KARAMALAKOVA Y., et al. antioxidantdepletion. Chem Res Toxicol.,20: 1769-1777, 2007.

14.Cavin, C., Delatour, T., Marin-Kuan, M., Fenaille, F., Holzhäuser, D., Guignard, G., Bezençon, C., Piguet, D., Parisod, V., Richoz-Payot, J., et al. Ochratoxin Amediated DNA and protein damage: Roles of nitrosative and oxidative stresses. Toxicol Sci, 110: 84-94,2009.

15.Cavin, C., Delatour, T., Marin-Kuan, M., Holzhäuser, D., Higgins, L., Bezençon, C., Guignard, G., Junod, S., Richoz-Payot, J., Gremaud, E., et al. Reduction in antioxidant defenses may contribute to Ochratoxin A toxicity and carcinogenicity. Toxicol. Sci., 96: 30-39, 2007.

16.Kamp, H., Eisenbrand G., Schlatter J., Wurth K., Janzowski C. Ochratoxin A: Induction of (oxidative) DNA damage, cytotoxicity and apoptosis in mammalian cell lines and primary cells. Toxicology, 206:413-425, 2005.

17.Stoev S., Anguelov G., Ivanov I., Pavlov D., Influence of ochratoxin A and an extract of artichoke on the vaccinal immunity and health in broiler chicks. Experimental and toxicologic pathology, 52(1), 43-55, 2000.

18.Poór, M., Kunsági-Máté, S., Bencsik, T., Petrik, J., Vladimir-Kneževi'c, S., K"oszegi, T., Flavonoid aglycones can compete with Ochratoxin A for human serum albumin: A new possible mode of action. Int. J. Biol. Macromol, 51: 2792832012

19.Ramyaa, P., Padma, V., Ochratoxininduced toxicity, oxidative stress and apoptosis ameliorated by quercetin-modulation by Nrf2. Food Chem Toxicol., 2013 doi: 10.1016/j.fct.2013.08.048.

20.Karamalakova, Y., Nikolova, G., Adhikari, M., Stoev, St., Agarwal, P., Gadjeva, V., Zhelev, Zh., Oxidative-protective effects of Tinospora cordifolia extract on plasma and spleen cells after experimental ochratoxicosis. Comp Clin Pathol., 1-9, 2018. https://doi.org/10.1007/s00580-0182761-y

21.Gholampour, A., Rahimi, K., Shateri, S., Ochratoxin: Contamination and Toxicity (A Review) Glob. Veterinaria, 8 :519-524, 2012.

22.O'Hara, M., Kiefer, D., Farrell K., and Kemper, K., A review of 12 commonly used medicinal herbs. Arch. Fam. Med., 7: 523-536, 1998. 
23.Patwardhan, B., and Gautam, M., Botanical immunodrugs: Scope and opportunities. Drug Discov. Today, 10: 495-502, 2005.

24.Umashanker, M., and Shruti, S., Traditional Indian herbal medicine used as antipyretic, antiulcer, anti-diabetic and anticancer: A review. Int. J. Res. Pharm. Chem., 1: 11521159, 2011.

25.Rahal M., Deb, R., Latheef, S., Samad, A., Tiwari, R., Verma A., Kumar, A., Dhama, K., Immunomodulatory and therapeutic potentials of herbal, traditional/indigenous and ethnoveterinary medicines. Pak J Biol Sci. 15(16):754-74, 2012.

26.Patwardhan, B., Vaidya, A., and Chorghade, M., Ayurveda and natural products drug discovery. Curr. Sci., 86: 789-799, 2004.

27.Boehm, K., Bussing, A., and Ostermann, T., Aromatherapy as an adjuvant treatment in cancer care: A descriptive systematic review. Afr. J. Traditional Complementary Altern. Med., 9: 503-518, 2012.

28.Simpson, T., Pase, M., and Stough C., Bacopa monnieri as an Antioxidant Therapy to Reduce Oxidative Stress in the Aging Brain, Evidence-Based Complementary and Alternative Medicine, 9: 2015.

29.Arora, R., CABI Publishing, Wallingford, Oxon, UK, 23, 1496, 2008.

30.Gupta, R., Sharma, V., Ameliorative effects of Tinospora cordifolia root extract on histopathological and biochemical changes induced by aflatoxin-b (1) in mice kidney. Toxicol Int. 18:94-8, 2011.

31.Cariddi, L., Sabini, M., Escobar, F., Montironi, I., Mañas, F., Iglesias, D., Comini, L., Sabini, L., Dalcero, A., Polyphenols as possible bioprotectors against cytotoxicity and DNA damage induced by ochratoxin A, Environ Toxicol Pharmacol., 39(3):1008-18, 2015

32.Tiwari, R., Chakraborty, S., Saminathan, M, Dhama, K., Singh, S., Ashwagandha (Withania somnifera): Role in safeguarding health, immunomodulatory effects, combating infections and therapeutic applications: A review. Journal of Biological Sciences, 14(2):77, 2014
KARAMALAKOVA Y., et al.

33. Chakraborty, S., and Pal, S.K., Plants for cattle health: A review of ethno-veterinary herbs in veterinary health care. Ann. Ayurvedic Med., 1: 144-152, 2012.

34.Sharma, P., Parmar, J., Sharma, P., Verma, P., and Goyal, P. K., Radiation-Induced Testicular Injury and Its Amelioration by Tinospora cordifolia (An Indian Medicinal Plant) Extract, Evidence-Based Complementary and Alternative Medicine, 9, 2011 doi:10.1155/2011/643847

35.Alok, S., Jain, S. K., Verma, A., Kumar, M., Mahor, A., \& Sabharwal, M. Plant profile, phytochemistry and pharmacology of Asparagus racemosus (Shatavari): A review. Asian Pacific Journal of Tropical Disease, 3(3): 242-251, 2013. http://doi.org/10.1016/S22221808(13)60049-3

36.Bhushan, P., Manish, G., Ethnopharmacology approaches for botanical immunomodulators and chemoprotectants in cancer therapy. Alternative Treatment For Cancer, 255284, 2007

37. Battacone, G., Nudda, A., Pulina, G., Effects of Ochratoxin A on Livestock Production. Toxins. 2(7):1796-1824, 2010. doi:10.3390/toxins2071796

38.Stoev, S.D., Djuvinov, D., Mirtcheva, T., Pavlov, D., Mantle, P. Studies on some feed additives giving partial protection against ochratoxin A toxicity in chicks. Toxicol. Lett. 135:33-50, 2002.

39. Gowda, N.K., Ledoux, D.R., Rottinghaus, G.E., Bermudez, A.J., Chen, Y.C., Efficacy of turmeric (Curcuma longa), containing a known level of curcumin, and a hydrated sodium calcium aluminosilicate to ameliorate the adverse effects of aflatoxin in broiler chicks. Poult. Sci. 87: 1125-1130, 2008.

40.Malekinejad, H., Mirzakhani, N., Razi, M., Cheraghi, H., Alizadeh, A., Dardmeh, F., Protective effects of melatonin and Glycyrrhiza glabra extract on ochratoxin A - induced damages on testes in mature rats. Human \& experimental toxicology. 30(2):110-23, 2011. 